\title{
Coronary aneurysm with double right coronary artery and fistula
}

\author{
Ying-Fu Chen, MD, PhD, ${ }^{\mathrm{a}, \mathrm{b}}$ Tsu-Ming Chien, MS, ${ }^{\mathrm{c}}$ and Chee-Siong Lee, $\mathrm{MD}^{\mathrm{d}}$
}

Video clip is available online.

A 64-year-old woman was referred to the Kaohsiung Medical University Hospital for evaluation of a mass adjoining the left cardiac border, identified on a chest roentgenogram (Figure 1, A). She had no history of Kawasaki's disease, chest trauma, or pulmonary problems, except a recent cough with whitish sputum. A grade 2 continuous murmur could be heard at the left upper sternal border. Enhanced computed tomography scans of the chest demonstrated a huge aneurysm located superiorly to the left atrium. A 3-dimensional computed tomography scan showed a giant coronary aneurysm and double right coronary artery (Figure 1, B). Left coronary angiography (Video 1) showed a giant aneurysm of the diagonal branch $(64 \times 48$ $\mathrm{mm}$ ) with distal occlusion. Right coronary angiography (Video 2) demonstrated a double right coronary artery originating from 2 separate ostia, and the inferior one showed normal angiography. The superior one (Video 3) gave rise to a coronary fistula draining into the main pulmonary artery. Both aneurysm and fistula were surgically corrected. Twelve months after surgery, the patient was doing well.

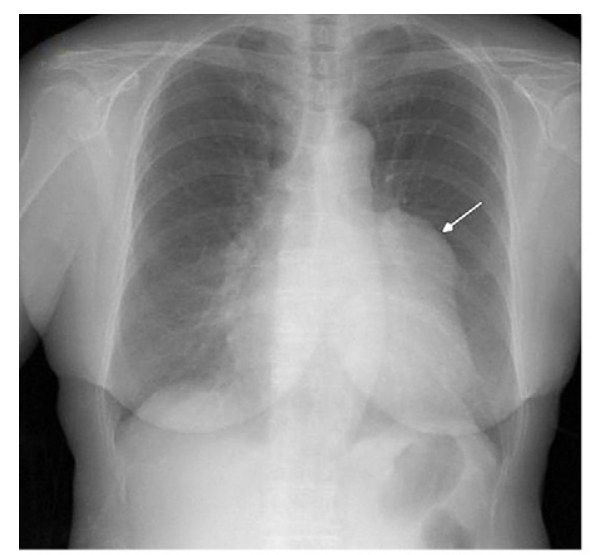

A

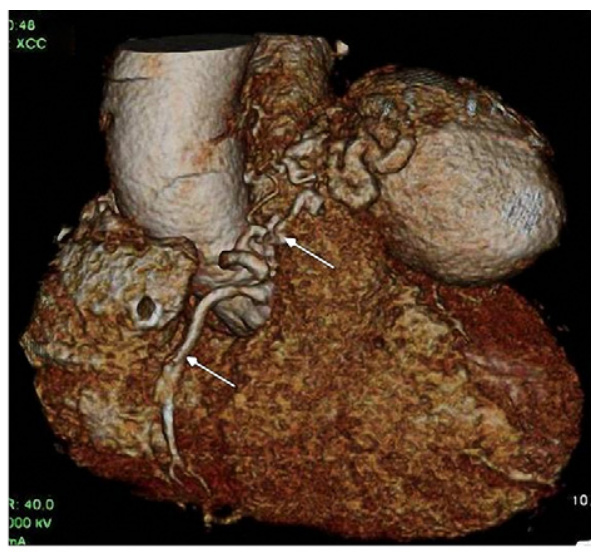

B

FIGURE 1. Chest roentgenogram identified a mass adjoining the left cardiac border (A, arrow). Three-dimensional computed tomography scan shows a giant coronary aneurysm and double right coronary artery (B, with the arrows showing the double right coronary artery).

\footnotetext{
From the Division of Cardiovascular Surgery, ${ }^{a}$ Kaohsiung Medical University Hospital, Kaohsiung, Taiwan; School of Graduate Medicine, ${ }^{\mathrm{b}}$ Kaohsiung Medical University, Kaohsiung, Taiwan; School of Post-baccalaureate Medicine, ${ }^{\mathrm{c}}$ Kaohsiung Medical University, Kaohsiung, Taiwan; and Division of Cardiology, ${ }^{\mathrm{d}}$ Kaohsiung Medical University Hospital, Kaohsiung, Taiwan.

Disclosures: Authors have nothing to disclose with regard to commercial support.

Received for publication Oct 10, 2010; accepted for publication Oct 22, 2010.

Address for reprints: Ying-Fu Chen, MD, PhD, Division of Cardiovascular Surgery,

Department of Surgery, Kaohsiung Medical University Hospital, 100, Shih-

Chuan 1st Rd, Kaohsiung, Taiwan (E-mail: yfchen@cc.kmu.edu.tw).

J Thorac Cardiovasc Surg 2011;141:585

$0022-5223 / \$ 36.00$

Copyright (C) 2011 by The American Association for Thoracic Surgery

doi:10.1016/j.jtcvs. 2010.10 .038
} 